\title{
ENDODONTIC MANAGEMENT OF THREE ROOTED MAXILLARY FIRST PREMOLAR AND PRESENCE OF
} \section{AN ASSOCIATED THREE ROOTED SECOND PREMOLAR: Case A CASE REPORT Report}

\author{
${ }^{1}$ Disha Mahore, ${ }^{2}$ Sharique Alam, ${ }^{3}$ Surendra Kumar Mishra, ${ }^{4}$ Ashok Kumar \\ ${ }^{1-4}$ Department of Conservative Dentistry and Endodontics \\ Dr. Z.A. Dental College, Aligarh Muslim University, Aligarh, India
}

\begin{abstract}
:
Failure to locate and disinfect all the root canals maybe a major reason for endodontic failure. A rare variant morphology of maxillary premolar has three separate roots with three root canals. The aim of this article is to report diagnosis and endodontic treatment of a maxillary first premolar with three roots and canals using reciprocating rotary instrumentation technique completed in single sitting. This paper also reports the presence of an associated three rooted second premolar in the same patient.
\end{abstract}

\author{
Key words: \\ Skeletal Class III \\ malocclusion, \\ dental decompensation, \\ horizontal. \\ Source of support : Nil \\ Conflict of interest: None
}

INTRODUCTION: Prevalence of three rooted first maxillary premolar is reported to be $0.6 \%$ in Asian ethnicity and $2.3 \%$ in Caucasian populations. In second maxillary premolar incidence reported is even lower at 0.3\%-2\%.[1-5] Vertucci et al.[4] studied 200 maxillary second premolars teeth, of which 150 (75\%) exhibited one canal at the apex, 48 had two canals at the apex, and 2 (7\%) showed three canals at the apex. There was one root in $39.5 \%$, two roots in $56.5 \%$, and three roots in $4 \%$ in maxillary first premolar.3. Sabala et al. in a study population of 501 reported 4 patients with three rooted maxillary first premolar and in all the cases it was present bilaterally. [6-7] Before endodontic treatment is initiated, the dentist should have an assessment of the configurations of the pulp anatomy he/she will treat. All root canals should be located as incomplete debridement will lead to almost certain failure. The introduction of single rotary nickel titanium system has expedited the biomechanical cleaning and shaping of root canals to allow completion of root canal treatment in a single visit. Reciproc (VDW, Munich, Germany) is a single file system which utilises reciprocating motion based on balanced force movement to effectively clean and shape the canals while minimising torsional and cyclic fatigue induced on the file.
The present case report describes the endodontic management of three rooted maxillary first premolar in a single appointment using single file Reciproc nickel titanium rotary instrumentation. This case also reports the associated presence of three rooted maxillary second premolar with three rooted maxillary first premolar in the same patient.

\section{CASE REPORT:}

The patient, a 24-year-old man, presented at the Department of Conservative Dentistry and Endodontics, AMU, Aligarh, reporting persistent pain which aggravated on cold stimulation on his upper right teeth. Considerable tooth loss by caries which infiltrated the pulp chamber was visible in the distal surface of tooth \#14. The patient's medical history was non-contributory. A diagnosis of asymptomatic irreversible pulpitis of \#14 was ascertained after clinical and radiographic examination. Intraoral periapical radiograph demonstrated presence of three distinct root apices in both maxillary first and second premolar. Two radiographs in mesial and distal angulation confirmed the presence of an extra accessory buccal root in both the maxillary premolars. The radiographs revealed a large root trunk with trifurcation of root canals into their respective roots in \#14 and \#15. \{Figure 1$\}$ 
Figure 1

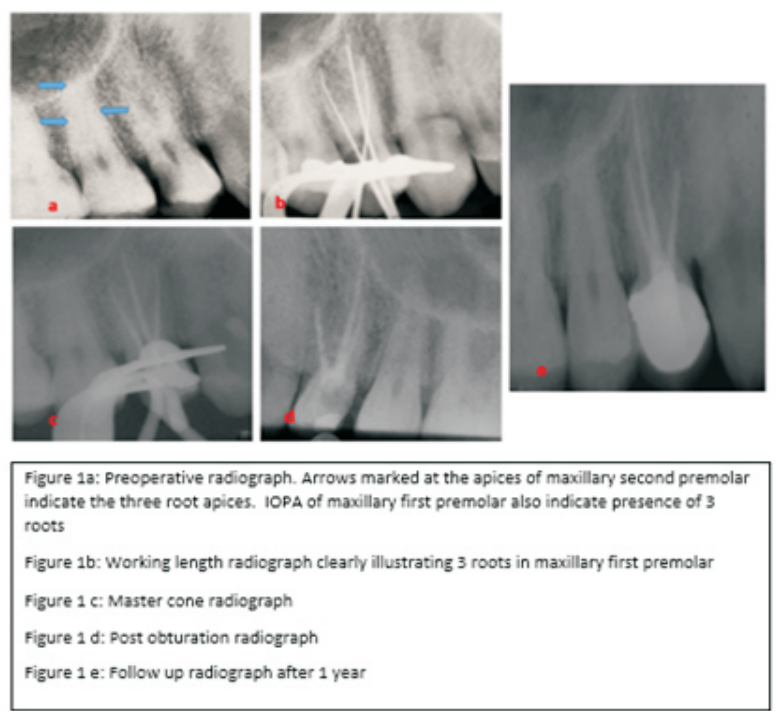

After local anaesthesia and rubber dam isolation, coronal access to the pulp chamber was made with Endo Access bur and Endo-Z bur (Dentsply Tulsa Dental, OK, USA). To confirm the presence of three roots, loupes (Neitz BLS-3, Tokyo, Japan) and radiographic examination were used. The three-root anatomy of a mesiobuccal, distobuccal, and palatal root, resulted in an access cavity with a T-shaped outline. \{Figure 2\} Examination of the pulp chamber floor using a DG-16 Endodontic Explorer (Hu-Friedy, Chicago, IL, USA) indicated three different root canal orifices of mesiobuccal, distobuccal, and palatal each corresponding to its respective root.

Figure 2

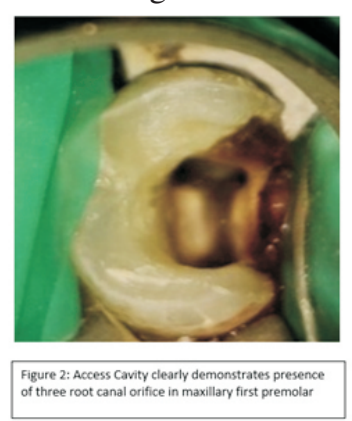

The working lengths were confirmed with the help of an apex locator (Root ZX; Morita, Tokyo, Japan). The canal were initially cleaned and shaped with $10 \mathrm{~K}$ and $15 \mathrm{~K}$ hand files (2 percent taper) (Dentsply Maillefer, Ballaigues, Switzerland) to produce a reproducible glide path for the rotary nickel titanium file. A nickel-titanium R25 Reciproc rotary file (Dentsply Maillefer, Ballaigues, Switzerland) in a X smart plus endomotor (Dentsply Sirona,UK) was selected to biomechanically clean and shape the three canals. The files were introduced with an in out pecking motion to gradually advance the file apically. A $10 \mathrm{~K}$ file was utilised between the instrumentation cycles to ensure canal patency.

During root canal preparation, copious irrigation was performed using $2.5 \%$ sodium hypochlorite solution and $17 \%$ ethylenediaminetetraacetic acid (Glyde File Prep, Dentsply Maillefer, North America). After completion of cleaning and shaping, canals were dried with absorbent paper points (Dentsply Maillefer) and then obturated using AH Plus sealer (Dentsply Maillefer, North America) and cold lateral compaction using master gutta percha of size 25 .

A final radiograph was taken to assess the length, taper and density of the obturation. \{Figure 1\}After completion of root canal treatment, the teeth was restored with a composite core (Z-100; 3M ESPE Dental Products, St. Paul, MN, USA) and cemented with PFM crown. After twelve months follow up, the tooth was completely asymptomatic and functional. \{Figure 1e $\}$.

DISCUSSION : A small subset of maxillary premolars may present with 3 roots and 3 root canals. These teeth usually have 2 buccal roots and 1 palatal root or less commonly 1 buccal root and 2 palatal roots, and each root usually has only 1 root canal. Three-rooted premolars are also known as ridiculous premolars, miniature 3-canalled molars, small molars, or minimolars. The detection and management of these premolars begin with careful clinical and radiographic examination. A wide mesiodistal dimension of the crown compared with its buccolingual dimension may indicate the presence of extra roots or root canals. Whenever the mesiodistal width of the mid root region on the preoperative radiograph is equal to or greater than the mesiodistal width of the crown, the tooth is likely to have an extra root.[8-9] Visualization of three-rooted maxillary premolars on the preoperative radiographs can often be difficult due to its lower incidence of occurrence. Whenever there is an indication of different anatomies, additional periapical radiographs should be exposed at mesial or distal horizontal angles.[10] Guidelines like "fast break" (Sudden narrowing or a disappearing pulp space) should be taken into consideration while assessing the pre-operative radiographs. If the root canal abruptly seems to straighten or broaden or if the course cannot be traced the presence of a second canal in the same root or of a canal in another root superimposed on the first one because of the radiographic projection should be suspected and anticipated.[11] 
In the present case three distinct root apices could be visualised which was confirmed with mesial and distal angulated radiographs. The dentinal map guided access cavity led to a $\mathrm{T}$ shaped access opening and revealed three orifices confirming the diagnosis of three rooted maxillary premolars. CBCT may be advised to detect aberrant root canal anatomy.[12]CBCT was not done in the present case keeping in perspective the radiation principle of ALARA( As Low as Reasonably Achievable). IOPA radiographs and the pulp chamber anatomy provided sufficient diagnostic information to guide the treatment and exposing patient to additional CBCT radiation exposure was therefore deemed not necessary in the present case.

In the present case three rooted first premolar was associated with three rooted second premolar which is an extremely rare occurrence. Sathyanarayanan et al. has reported a similar association of three rooted first and second premolar in the same patient.[13]

The root canals were prepared with reciprocation movement based single file Reciproc nickel titanium rotary system. The Reciproc files are manufactured from a heat treated nickel titanium alloy known as $\mathrm{M}$ wire technology. The reciprocating file movement and the $\mathrm{M}$ wire nickel titanium alloy increases the resistance to cyclic fatigue and improves the fracture resistance of the file.[14] Single file system and improved metallurgical properties of these file simplifies the biomechanical preparation of the canal. The expediency of the single file system allowed us to effectively clean shape and obturate all the three canals in a single visit.

CONCLUSION : Clear knowledge of the basic anatomy of the root canal and its possible variations, together with careful understanding of radiographs, access cavity modifications, negotiating all the orifices and predictably disinfecting the root canal system are essential elements for successful case management of irregular morphology of the root canal. Reciprocation based single file system like Reciproc may expedite the cleaning and shaping of root canals.

\section{REFERENCES :}

1. Carns EJ, Skidmore AE. Configurations and deviations of root canals of maxillary first premolars. Oral Surg Oral Med Oral Pathol 1973;36:880-886.

2. Walker RT. Root form and canal anatomy of maxillary first premolars in a southern Chinese population. Endod Dent Traumatol 1987;3:130-134.
3. Vertucci F J, Gegauff A. Root canal morphology of the maxillary first premolar. J Am Dent Assoc 1979;99:194-8

4. Vertucci F, Seeling A, Gillis R. Root canal morphology of the human maxillary second premolar. Oral Surg Oral Med Oral Pathol. 1974; 38: 456-64.

5. Loh HS. Root morphology of the maxillary first premolar in Singaporeans. Aust Dent J 1998;43:399-402.

6. Ingle JI, Bakland LK, Baumgartner JC (2008) Ingle's Endodontics 6e, (6thedn.) BC Decker Inc, Hamilton.

7. Sabala CL, Benenati FW, Neas BR (1994) Bilateral root or root canal aberrations in a dental school patient population. J Endod 20: 38-42.

8. Bellizzi R, Hartwell G. Evaluating the maxillary premolar with three canals for endodontic therapy. J Endod 1981;7:521-7.

9. Sieraski SM, Taylor GN, Kohn RA. Identification and endodontic management of three-canalled maxillary premolars. J Endod 1989;15:29-32.

10. Soares JA, Leonardo RT. Root canal treatment of threerooted maxillary first and second premolars - A case report. Int Endod J 2003;36:705-10.

11. Sieraski, S.M., Taylor, G.N., Kohn, R.A.,1989. Identification and endodontic management of threecanalled maxillary premolars. J Endod.15,29-32.

12. Abraham, D., Bahuguna,N., Manan, R.,2012. Use of $\mathrm{CBCT}$ in the successful management of endodontic cases. J Clin Imaging Sci.2,50.

13. Sathyanarayanan K, Srinivasan MR, Balagopal S, Poornima L. Report of occurrence and endodontic management of three-rooted maxillary first and second premolars in the same individual. Indian J Dent Res 2017;28:337-40

14. Al-Hadlaq SM, Aljarbou FA, AlThumairy RI. Evaluation of cyclic flexural fatigue of M-wire nickeltitanium rotary instruments. J Endod. 2010;36:305-7

\section{CORRESPONDING CONTRIBUTOR:}

\section{Dr. Sharique Alam}

Assistant Professor

Department Of Conservative Dentistry And Endodontics

Dr Z.A. Dental College,Aligarh Muslim University

Aligarh. India

E-mail-Sharique2004@gmail.com 